\title{
Ratio of False Positive Results of Growth Hormone Stimulation Tests (Arginine and Insulin)
}

\author{
Yukihiro Hasegawa, Tomonobu Hasegawa, Shinobu Kotoh and Yutaka Tsuchiya \\ Division of Endocrinology and Metabolism, Tokyo Metropolitan Kiyose Children's Hospital, \\ Tokyo, Japan
}

\begin{abstract}
We studied the false positive ratios of arginine and insulin tests in short children. Totally, the false positive ratio was about $22 \%$. There was no statistical difference in the false positive ratios between arginine tests and insulin tests. It did not seem that the false positive ratio was influenced by height or IGF-I levels.
\end{abstract}

Key words: false positive results, arginine and insulin tests, IGF-I, height

It is well known that there are false positive and negative results of $\mathrm{GH}$ stimulation tests [1-7]. For example, the false positive results of arginine and insulin tests were reported to be $20-30 \%$ in normal short children [2-7]. After the development of a sensitive $\mathrm{GH}$ assay such as IRMA, the ratio of false positive results of $\mathrm{GH}$ stimulation tests remains to be clarified. We studied the false positive ratio of insulin and arginine tests.

\section{Subjects}

Subjects were 32 control children (CC: height $>$ mean $-2 \mathrm{SD},-0.99 \pm 1.28 \mathrm{SD})$ and 127 normal short children (NS: height $<$ mean $-2 \mathrm{SD},-3.32 \pm 0.86 \mathrm{SD})$. In normal short children, at least one of the GH peaks of

Correspondence: Dr. Yukihiro Hasegawa, Chief, Division of Endocrinology and Metabolism, Tokyo Metropolitan Kiyose Children's Hospital, 1-3-1, Umezono, Kiyose, Tokyo 204 Japan
$\mathrm{GH}$ stimulation tests was over $10 \mathrm{ng} / \mathrm{ml}$.

\section{Method}

(1) GH was measured by RIA (Eiken Kit) and IRMA (Eiken Kit). The results were evaluated after all RIA GH levels were calculated into IRMA GH levels according to our hospital's relation between RIA and IRMA GH assay (IRMA GH $=0.88^{*}$ RIA GH-1.39). IGF-I was measured by RIA with or without acid ethanol extraction. Similarly, all the IGF-I levels without the extraction were calculated into those with the extraction.

(2) Insulin and arginine tests were done as follows (Table 1): arginine infusion $(0.5 \mathrm{~g} / \mathrm{kg}$ for $30 \mathrm{~min})$, followed by insulin injection $(0.1$ $\mathrm{U} / \mathrm{kg}$ one IV injection) two and half hours after starting the arginine infusion. Blood was taken $0,30,60,90,120,150 \mathrm{~min}$ after arginine infusion and $0,15,30,45,60,90,120$ min after insulin injection. 
Table 1. Arginine and Insulin tests. (Insulin is injected $2.5 \mathrm{hr}$ after starting arginine infusion)

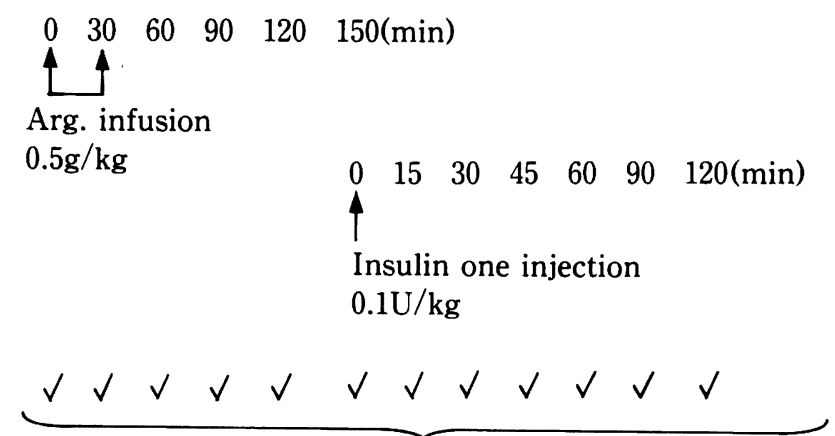

blood sampling for $\mathrm{GH}$

Table 2. False positive ratio of arginine (Arg.) and insulin (Ins.) tests in CC and NS

$\begin{array}{ccc}\text { CC } & \text { Arg. } & 29 \%(\mathrm{n}=28) \\ & \text { Ins. } & 19 \%(\mathrm{n}=32) \\ & \text { Arg. \& Ins. } & 23 \%(\mathrm{n}=60) \\ & \text { Arg. } & 25 \%(\mathrm{n}=126) \\ \text { NS } & \text { Ins. } & 19 \%(\mathrm{n}=127) \\ & \text { Arg. \& Ins. } & 22 \%(\mathrm{n}=253)\end{array}$

(3) All the data were shown as mean $\pm \mathrm{SD}$, and statistical analysis was done by chi-square test.

\section{Results}

(1) On the presumption that $\mathrm{GH}$ secretion status was normal if any one of the $\mathrm{GH}$ peaks among the $\mathrm{GH}$ stimulation tests was over 10 $\mathrm{ng} / \mathrm{ml}$, the false positive ratios of these two tests ( $\mathrm{GH}$ peaks $<10 \mathrm{ng} / \mathrm{ml}$ by IRMA assay) were $23 \%$ and $22 \%$ in CC and NS, respectively (Table 2). There was no statistical difference in the ratio of the false positive results between $\mathrm{CC}$ and NS. The false positive ratios of our arginine and insulin tests in total subjects were $25 \%(n=154)$ and $19 \%(n=159)$, respectively. There was no statistical difference between the false positive ratio of the arginine test and that of the insulin test.

(2) When we divided the subjects into three age groups, namely the group at the age of 1-4 years, that at the age of 5-9 years and that at the age of $10-15$ years, the false positive ratios of these three groups were $12 \%(n=68), 20 \%$ $(n=108)$, and $30 \% \quad(n=147)$, respectively. There was no statistical difference of the false positive ratios among any two out of the three age groups.

(3)When we divided the patients with NS into two groups based upon their IGF-I levels, namely the group with normal IGF-I levels ( $>$ 5 th percentile of normal control children [8]) and that with low IGF-I levels $(<5$ th percentile), the false positive ratios of these two groups were $18 \% \quad(n=77)$ and $25 \% \quad(n=36)$, respectively. There was no statistical difference of the false positive ratio between these two groups.

(4) When we divided the patients with NS into two height groups, namely the group with heights ranging from mean $-2 \mathrm{SD}$ to mean $-4 \mathrm{SD}$ and the group with heights under mean $-4 \mathrm{SD}$, the false positive ratios of these two groups were $21 \%(n=199)$ and $21 \%(n=$ $52)$, respectively. There was no statistical difference of the false positive ratio between these two height groups or between either height group and CC group.

\section{Discussion}

There have been several classical reports about the false positive ratios of traditional GH stimulation tests [1-7]. They are usually $20-30 \%$, which is quite similar to our results of arginine and insulin tests.

Although the false positive ratios in $\mathrm{CC}$ and NS did not significantly change with age, there was a tendency for the false positive ratio to increase with age. This difference with age may be because we did not "prime" for older patients. However, even at younger ages, the false positive ratios were not so low (12\% and $20 \%$ ).

We have reported the weak relation between IGF-I and height.[9] in normal and short children. IGF-I is well known to be 
mainly regulated by $\mathrm{GH}$ and height was reported to correlate with $\mathrm{GH}$ secretion status [10]. However, our false positive ratios of arginine and insulin were not dependent upon IGF-I levels or heights in short children. Thus, the false positive ratios of arginine and insulin tests in our study did not seem to reflect the difference of IGF-I levels or heights (difference of GH secretion status) among our subjects but just reflected the limitations of our arginine and insulin tests themselves.

\section{References}

1. Frasier SD. A review of growth hormone stimulation tests in children. Pediatrics 1974: 53; 929-37.

2. Root AW, Rosenfield RL. Bongiovanni AM, Everlein WR. The plasma growth hormone response to insulin-induced hypoglycemia in children with retardation of growth. Pediatrics. 1967: 39; 844.

3. Parker ML, Hammond JM, Daughaday WH. The arginine provocative test: an aid in the diagnosis of hyposomatotropism. $\mathrm{J}$ Clin Endocrinol 1967: 27; 1129.

4. Ratti S, Davis WT, Blizzard RM. A comparison of the effects of insulin hypo- glycemia and arginine infusion on release of human growth hormone. Lancet 1967: 2; 1182.

5. Kaplan SL, Abrams CAL, Bell JJ, Conte FA, Grumbach MM. Growth and growth hormone: Changes in serum level of growth hormone following hypoglycemia in disorders of growth. Pediat. Res., 1968: 2: 43.

6. Root AW, Saenz-Rodriquez C, Bongiovanni AM, Everlein WR. The effect of arginine infusion on plasma growth hormone and insulin in children. J Pediat 1969: 74; 187.

7. Penny R, Blizzard RM, Davis WT. Sequential arginine and insulin tolerance tests on the same day. J Clin Endocrinol Metab. 1969: 29; 1499-501.

8. Hasegawa $\mathrm{Y}$, Hasegawa $\mathrm{T}$, Kotoh S, Tsuchiya $\mathrm{Y}$, Harada $\mathrm{A}$, Horie $\mathrm{H}$, et al. The clinical utility of IGF-I in the diagnosis of growth hormone deficiency. Clin Endocrinol 1992: 40; 1107-10 (in Japanese).

9. Hasegawa Y, Hasegawa T, Kotoh S, Tsuchiya $\mathrm{Y}$, et al. Relationship between height and IGF-I and IGFBP-3 levels. Clin Pediatr Endocrinol 1992: 1(2); 159 (Abstract).

10. Albertsson-Wikland K, Rosberg S. Analysis of 24-hour growth hormone profiles in children: relation to growth. J Clin Endocrinol Metab 6988: 67; 493-500. 